\title{
Rational and Emotional Advertising: A bibliometric Analysis (1990-2020)
}

\author{
Habiba Elbardai ${ }^{1}$, Kamal Lakhrif ${ }^{2}$ \& Hélène Yildiz $^{3}$ \\ ${ }^{1}$ International University of Agadir, Universiapolis. Morocco \\ ${ }^{2}$ Ibn Zohr University, FSJES Agadir, Morocco \\ ${ }^{3}$ Lorraine University-Nancy, France \\ Correspondence: Kamal Lakhrif, Ibn Zohr University, Morocco. E-mail: k.lakhrif@uiz.ac.ma
}

Received: September 16, $2021 \quad$ Accepted: October 28, $2021 \quad$ Online Published: November 8, 2021

doi:10.5539/ijms.v13n4p16

URL: https://doi.org/10.5539/ijms.v13n4p16

\begin{abstract}
This study analyzes trends in the scientific literature on the concepts of rational and emotional advertising. The article presents a bibliometric analysis of 96 studies on rational and emotional advertising, taken from the Web of Science database (WOS) for the period 1990-2020. The study categorizes these documents according to bibliographic indicators, i.e., most productive authors, year of publication, countries with the highest productivity rate, the journals and universities that published the most on this topic, language, type of research and field of research. This analysis provides an overview of the nature and trends of research on rational and emotional advertising. The results of the analysis reveal the research weakness for this concept, especially in terms of definitions and conceptualization. Also, the results highlight the fragmented nature of the themes addressed in the various research articles on rational and emotional advertising.
\end{abstract}

Keywords: rational and emotional advertising, bibliometric analysis, Web of Science

\section{Introduction}

The considerable impact of rational and emotional advertising has led to an exponential development of this research topic in various science disciplines over the last five years. Indeed, this ability to act on behavior in a subtle and massive way has aroused the interest of public organizations and institutions, and researchers throughout the world especially in the United States and England. Governments have also been quick to employ messages based on rational and emotional advertising to point their citizens in the right direction.

Thus, due to a strong growth of the literature on rational and emotional advertising and questions of all kinds surrounding this concept, this study analyzes and shows the development of rational and emotional advertising for the past 30 years. In addition, this study examines the most common themes in the literature to identify potential weaknesses and gaps in scientific research on rational and emotional advertising. To achieve these objectives, this research consists of a bibliometric analysis based on data (articles, books and other documents) available on the Web of Science database. This study analyzes 96 research papers on rational advertising over the period 1990-2021. The study deals with articles from 1990, as the oldest article on rational and emotional advertising in the Web of Science dates from that year. For this purpose, our bibliometric analysis is conducted to answer the following research questions: $R Q 1$ : How has the advertising literature addressing rational and emotional concepts evolve so far? $R Q 2$ : What are the most cited journals worth consulting for future research in this field? RQ3: What are the research concepts related to rational and emotional advertising and which ones deserve further consideration in prospective advertising studies?

In order to answer those questions, we chose the bibliometric analysis because it represents an appropriate tool, since it gives scholars and researchers a solution to detect the evolution and different aspects related to a specific field of study (Broadus, 1987; Cuccurullo et al., 2016; Merig'o et al., 2015). In this paper we will categorize the scientific production related to rational and emotional advertising published to date. In addition, this paper offers researchers an overview of the literature and its evolution until today and proposes possible future research venues.

Moreover, we used several indicators in order to identify the most significant papers, journals, authors, universities and countries. Our analysis shows that published research related to rational and emotional 
advertising, had begun more than 30 years ago and grows continually over the years. We had been able to notice that the topic was more developed by authors coming from developed countries (e.g., USA and England). Those ones are ranked in the first position concerning the number of published documents, citations and journals' origins. In this logic, the study results proved that most of journals are related to business field, especially advertising and marketing signifying the need to focus on different journals on this topic.

Furthermore, the performed science mapping allows the structure identification of the concepts under study. In fact, the conceptual structure was analyzed based on keywords' co-occurrences that reveal the existence of three concepts clusters directly linked to rational and emotional advertising: (i) advertising appeal, (ii) consumer behavior, and (iii) decision making. Social configuration was analyzed through co-authorships and shown that the most pertinent authors act scientifically by their own with no connections between them, which prove a lack of scientific collaboration. Finally, the intellectual structure was studied based on references' co-occurrences to highlight which scientific papers constitute the most influenced in the studied topic over the years.

The main objective of this work is to allow researchers to have a clear vision about rational and emotional literature development in the past 30 years. From this work, researchers can have an idea about the fields where rational and emotional advertising were studied. Our analysis will summarize the previous studies according to bibliographic indicators, namely by most productive authors, year of publication, countries with the highest productivity rate, the journals and universities that published the most on this topic, language, type of research and field of research. Our analysis will illustrate the author's collaboration by field, subject and university. It will indicate the most cited authors and the most ranked journals chosen by researchers to publish their work on rational and emotional studies.

This work is organized as follows. Section 1 presents rational and emotional advertising literature review. Section 2 describes the adopted methodology. Section 3 discusses the results of the bibliometric analysis. Section 4 represents avenues for future research paths and finally, section 5 presents the conclusion, limitations and research paths emerging from this study.

\section{Literature Review}

In recent years, marketing research has generated increased interest in advertising effectiveness study, and researchers have attempted to identify the types of messages that have a significant impact on consumer persuasion. This acceleration is explained by the development of advertising expenditure, which generally represents a significant percentage of companies' turnover ( $\$ 276$ billion in 1998 versus $\$ 600$ billion in 2021 based on Statista research department, 2019).

In general, research has focused on the effectiveness of soft-sell and hard-sell advertising approaches, commonly referred as "emotional" and "rational" advertising. In fact, more than 75 surveys related to these message categories were identified by some researchers (Okazaki et al., 2010), following an extensive review of national and international advertising media.

The first emotional and rational advertising definitions, were proposed in Printer'sink magazine in 1920. In fact, written articles in this magazine proposed that rational advertising deliver informative information about a product without arousing the reader or creating sensations, like emotional advertising does. Another article published in the same magazine in 1973, added that rational advertising focuses on product functional aspects by presenting arguments in favour of buying a good.

Over the years, new emotional and rational advertising features have complemented this definition. Indeed, Mueller (1987) developed the use of moving stories in emotional advertising and the focus on the brand and the product name in rational advertising. Also, Alden et al. (1999) attempted to enrich the definitions with new dimensions, namely the comparison between brands in rational advertising and the use of the image to create associations with the product in emotional advertising.

According to recent definitions by Okazaki et al. (2010), an emotional message is a message in which human emotions are solicited to induce an emotional reaction from the consumer. These messages tend to be subtle and indirect and an image or atmosphere can be conveyed through a beautiful scene or the development of a moving story, or through some other indirect mechanism.

On the other hand, the objective of a rational message is to solicit the recipient's rational thinking. These messages tend to be direct, focusing on a commercial orientation and often specifying the brand name and product characteristics. There is often explicit reference to factual information such as comparisons with competing or specific products with the distinctive characteristics of the product, which give it an advantage in terms of performance or other relevant dimension for consumers (Okazaki et al., 2010). 
These definitions lead us to make two observations: the first, is the lack of consensus on the definition of emotional and rational advertising, the second is that researchers follow a logic that qualifies advertising as emotional or rational. The disadvantage of this approach is its dichotomous nature (emotional vs rational), and thus does not take into account the possibility of advertising messages containing both emotional and rational characteristics.

In this perspective, Campbell et al. (2020) demonstrate the value of treating hard-sell and soft-sell as multidimensional, complementary and combinatorial marketing approaches that allow the message to be both «subjective» (soft-sell) and «precise» (hard-sell), or both "creative" (soft sell) and "informative" (hard sell). The second debate on emotional and rational advertising is about their effectiveness. In fact, studies have analyzed their divergent impact on the persuasion. For example, the meta-analysis done by Hornik et al. (2016), shows that advertising messages that trigger positive emotions are more compelling than rational messages.

Okazaki et al. (2010) confirmed that a rational message improves positively the consumer attitudes towards the brand as it is associated with a higher level of credibility compared to an emotional message. Some studies (Safraou-Ouadrani et al., 2010), have linked the efficiency of the two advertising approaches to the consumers' ability for information processing, assuming that people will be more persuaded by an emotional message than by a rational message.

Similarly, Wei Chen et al. (2007) attempted to explain the efficacy of advertising messages by the nature of the product being advertised and the recipient's motivation to process the information. However, Butt et al. (2017) argue that the efficiency of soft-sell and hard-sell approaches is linked to the country's development. Their study suggests that in a developing market, the hard-sell approach is perceived as more credible and leads to a stronger buying intention than the soft-sell approach.

On the other hand, many authors made a link between the efficiency of rational and emotional advertising and the consumer attitude (Mehta, 2000; Pollay \& Mittal, 1993). In fact, the attitude represents a person's feeling of favorableness or un-favorableness towards some stimulus object (Ajzen, 2001; Scholderer, 2011). An attitude is a predisposition to respond positively or negatively to a particular advertising; it is a message content evaluation in affective and cognitive terms (Lutz et al., 1983). In addition, it was found that the attitude is the main predictor of rational and emotional advertising effectiveness (Mehta, 2000). Furthermore, Mitchell and Olson (1981), explained that attitudes toward rational and emotional advertisements determine the attitudes towards brands as well as consumer behavior (Tsang et al., 2004). The majority of researchers (e.g., Coulter, 2001; Loda \& Coleman, 2005; Hennig-Thurau et al., 2007; Haisley \& Loewenstein, 2011; Purnawirawan et al., 2012; Ivanov et al., 2013) found that rational and emotional sequences in advertising have an effect on consumer attitudes towards a given brand and/or product.

Another controversial debate involves the efficiency difference for emotional and rational approaches, depending on the cultural context. Alden et al. (1999) have assumed that the emotional message leads to homogeneous understanding and perception in different target markets, while the rational message is not perceived in the same way in different cultural contexts.

According to Alden et al. (1999), emotional advertising is more appropriate than rational advertising when it comes to developing a global campaign. Also, Okazaki et al. (2010) suggested that emotional messages, based on image are more effective than rational messages, based on strong arguments, in terms of attitude, credibility, irritation, and intent. This ties with the research of Elinder (1965) and Fatt (1967), who found that the development of societies increasingly eliminates cultural barriers and allows the emergence of a standardized international communication.

However, many authors (Buzzels, 1968; Quelch \& Hoff, 1986; Luqmani et al., 1989; Haque et al., 2010) don’t agree with the fact that emotional advertising is the right approach to standardized advertising. They doubt the impact of the same advertising message in different cultural contexts and therefore recommend to adapt the message. In the same perspective, El Bardai (2020) proposes that the effectiveness of the soft-sell and hard-sell approaches can be attributed to the degree of religiosity of the target that plays an essential role in consumer preferences.

\section{Methodology}

In this work, our methodology consists of a bibliometric analysis study. It can be defined as an Infor-metrics that allow to measure the impact of scientific publications and their related level of knowledge dissemination through quantitative perspective, which is useful for organizing information in a specific thematic area (Broadus, 1987; Cuccurullo et al., 2016; Merig'o et al., 2015). Bibliometric analysis is also a form of scientific publication 
analysis that evaluates the evolution of the knowledge of a specific research theme and assesses the scientific quality and predominance of works and sources (Bouyssou \& Marchant, 2011; Daim et al., 2006). Furthermore, bibliometric analysis enables researchers to explore a large amount of data from the literature while, at the same time, keeping a high level of rigor, transparency and replicability (Dada, 2018; Rey-Martí et al., 2016).

To implement the current bibliometric analysis on rational and emotional advertising, this study analyzed the most productive authors, the most fertile journals on rational and emotional advertising and the countries and languages that publish the most on this topic. This bibliometric analysis followed six steps: 1) defining the field under study, 2) selecting the database, 3) adjusting the research criteria, 4) compiling categories of bibliographic information, 5) codifying the recovered material, and 6) analyzing the information.

\section{a. Database Choice}

Bibliometric analysis consists of collecting data from an appropriate database (Broadus, 1987). Although, several bibliometric databases exist, for the purpose our study, we use Web of science (WoS) from Clarivate database. This choice was made because, the WoS database covers more than 15,000 journals and over 90 million documents (Canio et al., 2021). The WoS database allows researchers to access articles from scientific journals, books and other academic documents in all fields of science. In addition, the Clarivate analysis WoS reviews have impact factors in the Journal Citation Report (JCR). That's why, scholars have recognized it as having higher standards quality than Scopus (Merig'o et al., 2015). This study analyzes the articles, procedural documents, and chapters on books and editors' notes from 1990 to 2020.

\section{b. Data extraction}

Cadavid-Higuita et al. (2012) propose three categories of indicators. The first one is quantity, which measures productivity in terms of the number of publications. The second one is quality, which measures the impact of a publication according to the number of citations that publication receives. Finally, the structural indicator measures the relationship between publications. The bibliometric indicators used in this study are quantitative and qualitative indicators, because the study tries to measure the amount of interest in rational and emotional advertising in recent years.

To collect data from WoS, we adopted an encoding procedure which consists of encoding the topic field using a search string. As our goal is to explore studies that were conducted about the efficiency of both rational and emotional advertising, we typed the keywords: "rational and emotional advertising" on WoS search bar.

The research reveals results that contain the selected topic words, in different documents format, title, abstract and authors. The research was conducted in March 2021 and took into consideration all research documents from 1990 to 2020. In order to be more specific regarding the results, we used filters to eliminate the references that are not in the English language and those that did not go through a double blinded reviewed (TV interview; letters; discussions...), (Noyons et al., 1999).

The WoS database shows 258 references for the topic "rational and emotional advertising". However, after using research filters to reduce the number of results and better meet our research criteria, we limited the results to 96 articles as shown in Figure 1.

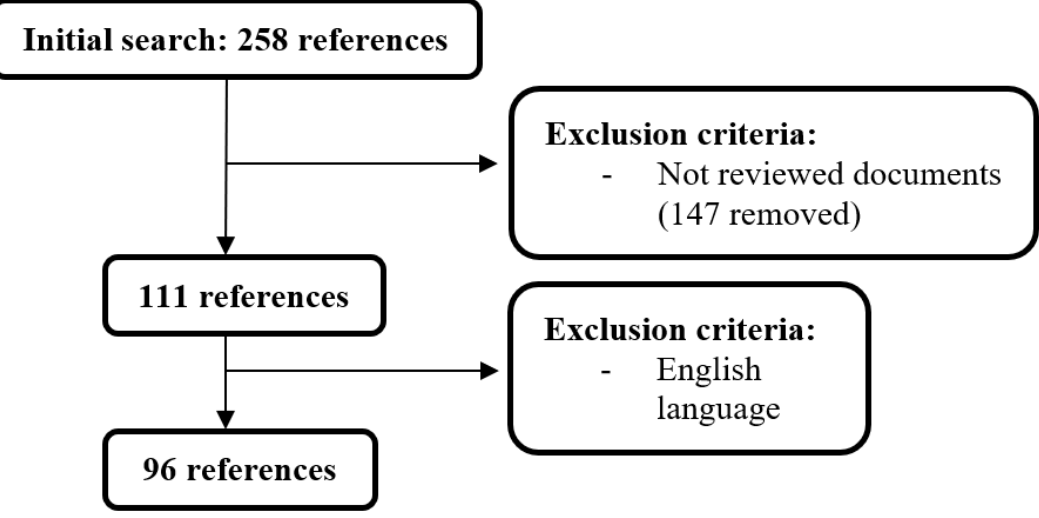

Figure 1. The different phases of data extraction (Author's own elaboration) 


\section{c. Performance analysis indices}

In order to evaluate the collected data (Topic; Articles; Journals; Authors; countries; affiliations; countries and citations), we adopted the h-index as an indicator. In fact, the h-index indicates the number of publication that have received at least a given number "h" citations (Hirsch, 2005). It is considered by researchers as a good and strong indicator to evaluate the productivity and relevance of scientific production (Vanclay, 2007). Also, this indicator in known for its easy interpretability (Hirsch, 2005).

\section{d. Science mapping}

The bibliometric analysis uses science mapping as a technique to visualize properly the concepts structure and the links between the components and their evolution over time (Borner et al., 2003; Cobo et al., 2012). In fact, science mapping highlights the links between the intellectual structure (authors, journals and documents). In order to perform the analysis, we followed the steps described by Cobo (2012). These consist of using co-occurrence and co-citation analysis (Cobo, 2012; Waltman, 2010).

To study the conceptual structures of rational and emotional advertising, we used a co-occurrence analysis based on keywords plus. Therefore, after discarding isolated items, we got 27 items grouped together in to 5 clusters. We chose an association strength method (Waltman, 2010) with a minimum word frequency of 4 . Moreover, we performed a co-authorship analysis based on co-authored documents (Cobo, 2012), in which 265 authors represented the unit of this analysis. Our analysis is based on the association strength normalization, as it was recommended by Waltman (2009). Furthermore, we didn't neglecte isolated nodes to understand more the existing collaboration between researchers in the studied topic. We also highlight the relationship of the studied topic according to the number of citations by countries and universities. Finally, we made a historiograph (Garfield, 2004), representing the evolution of the 20 most cited research paper published over the 30 past years about the use of rational and emotional advertising.

\section{Results of the Bibliometric Analysis}

In this section, we are going to present our bibliometric analysis results. The main objective of this section is to answer our study research questions.

\section{a. The evolution of articles over time}

The first studies in rational and emotional advertising in the WoS started in 1992, when Manrai et al. (1992) published their research paper in which they studied the implication of rational and emotional advertising appeal for creative strategy in TV commercials. Research on this topic has been published for more than 28 years. This topic got the scientific community attention since 1992 (see Figure 2).

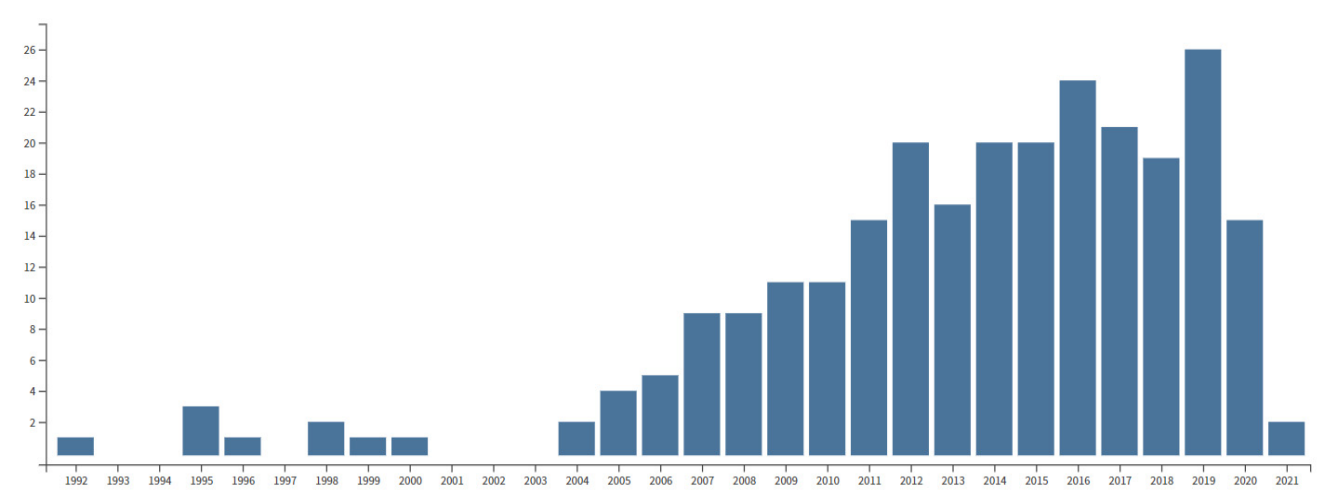

Figure 2. Total publication by year (Clarivate WoS, 2021)

Therefore, the total scientific production rate in rational and emotional advertising increased from 2004 to 2020 , reaching its peak in 2019, when the number of published documents reached 30 publication compared with previous years, where the number were relatively low.

In order to identify the articles that have most interested academic researchers in the field of rational and emotional advertising, we analyzed the number of documents citations (Merig'o et al., 2015). Indeed, we focused on the total citations (TC) and the average number of citations by year (TC/Y). The results of the top 10 
most cited articles extracted from WoS are represented in the following table:

Table 1. Citation analysis of the 10 most relevant documents in the dataset ordered by the total number of citations received (TC)

\begin{tabular}{|c|c|c|c|c|c|c|}
\hline Rank & Author(s) & Title & Year & Journal & TC & $\mathbf{T C} / \mathbf{Y}$ \\
\hline 1 & Pawle et al. & $\begin{array}{l}\text { Measuring emotion - Lovemarks, the future } \\
\text { beyond brands }\end{array}$ & 2006 & $\begin{array}{l}\text { Journal of Advertising } \\
\text { Research }\end{array}$ & 89 & 5.56 \\
\hline 2 & Heath et al. & $\begin{array}{l}\text { Brand relationships: Strengthened by emotion, } \\
\text { weakened by attention }\end{array}$ & 2006 & $\begin{array}{l}\text { Journal of Advertising } \\
\text { Research }\end{array}$ & 71 & 4.44 \\
\hline 3 & Mehta et al. & $\begin{array}{l}\text { Reconsidering recall and emotion in } \\
\text { advertising }\end{array}$ & 2006 & $\begin{array}{l}\text { Journal of Advertising } \\
\text { Research }\end{array}$ & 65 & 4.06 \\
\hline 4 & Buck et al. & $\begin{array}{l}\text { Emotion and reason in persuasion - Applying } \\
\text { the ARI model and the CASC Scale }\end{array}$ & 2004 & $\begin{array}{l}\text { Journal of business } \\
\text { research }\end{array}$ & 48 & 2.67 \\
\hline 5 & Silva et al. & $\begin{array}{l}\text { Functional or emotional? How Dutch and } \\
\text { Portuguese conceptualise beer, wine and } \\
\text { non-alcoholic beer consumption }\end{array}$ & 2016 & $\begin{array}{l}\text { Journal of Food quality } \\
\text { and preference }\end{array}$ & 44 & 7.33 \\
\hline 6 & Page et al. & $\begin{array}{l}\text { Emotional and rational product appeals in } \\
\text { televised food advertisements for children: } \\
\text { analysis of commercials shown on US } \\
\text { broadcast networks. }\end{array}$ & 2007 & $\begin{array}{l}\text { Journal of child health } \\
\text { care }\end{array}$ & 40 & 2.67 \\
\hline 7 & Zhang et al. & $\begin{array}{l}\text { Be rational or be emotional: advertising } \\
\text { appeals, service types and consumer responses }\end{array}$ & 2014 & $\begin{array}{l}\text { European journal of } \\
\text { Marketing }\end{array}$ & 31 & 3.88 \\
\hline 8 & $\begin{array}{l}\text { Chaudhuri, A.; } \\
\text { Buck, R. }\end{array}$ & $\begin{array}{l}\text { Media difference in rational and emotional } \\
\text { responses to advertising }\end{array}$ & 1995 & $\begin{array}{l}\text { Journal of broadcasting } \\
\text { and electronic media }\end{array}$ & 31 & 1.15 \\
\hline 9 & Mattila, A.S. & Do emotional appeals work for services? & 1999 & $\begin{array}{l}\text { International journal of } \\
\text { service industry } \\
\text { management }\end{array}$ & 30 & 1.3 \\
\hline 10 & Elsaesser et al. & $\begin{array}{l}\text { Rational and emotional factors of customer } \\
\text { satisfaction and brand loyalty in a } \\
\text { business-to-business setting }\end{array}$ & 2017 & $\begin{array}{l}\text { Journal of business and } \\
\text { industrial marketing }\end{array}$ & 28 & 5.6 \\
\hline
\end{tabular}

Source: Authors' own elaboration.

According to the table, Buck appears twice in this list and can be considered as a reference of rational and emotional advertising. After Buck et al. (2004), the most cited articles are those by Pawle et al. (2006), Heath et al. (2006) and Mehta et al. (2006) containing studies that focused on the emotion measures. Followed by Silva et al. (2017) and Page et al. (2007) who analyzed, the effect of food rational and emotional advertising on consumer's responses.

\section{b. Articles' countries of origin}

Our database contains a total of 265 authors coming from 164 institutions, who contributed in publishing 96 articles in 30 different countries. We had noticed that only two articles are single-authored and 94 others are multi-authored.

We observed that, of the 30 countries involved in the studied topic, the top countries in terms of published articles are developped countries (USA, England, Australia and China). Table 2 represents the top 10 countries sorted by the total number of publications, citations received, citation per year and h-index (Merig'o et al., 2015).

Table 2. Countries with the highest rate of productivity

\begin{tabular}{llllll}
\hline Rank & Country & TP & TC & C/P & h-index \\
\hline $\mathbf{1}$ & USA & 32 & 524 & 20.15 & 13 \\
$\mathbf{2}$ & England & 13 & 202 & 15.54 & 9 \\
$\mathbf{3}$ & Australia & 8 & 115 & 14.38 & 6 \\
$\mathbf{4}$ & China & 8 & 106 & 13.25 & 5 \\
$\mathbf{5}$ & South Korea & 8 & 93 & 11.63 & 5 \\
$\mathbf{6}$ & Taiwan & 6 & 43 & 7.17 & 4 \\
$\mathbf{7}$ & France & 5 & 110 & 22 & 5 \\
$\mathbf{8}$ & Spain & 5 & 58 & 11.6 & 2 \\
$\mathbf{9}$ & Canada & 4 & 57 & 14.25 & 2 \\
$\mathbf{1 0}$ & Iran & 4 & 31 & 7.75 & 3 \\
\hline
\end{tabular}

Source: Authors' own elaboration. 
Table 2 shows that, the USA is the leader for total published paper and relevance concerning rational and emotional advertising, followed by England, Australia, and China. Other countries, such as France and South Korea, rise in relation to the total citations received.

\section{c. Authors}

In order to evaluate the authors who wrote about rational and emotional advertising, we took into consideration the author's productivity and its impact. In fact, we made an overview of the top 20 authors among 265 sorted by their productivity for the last 28 years. The author's productivity was evaluated through the number of articles published in a given period of time. Also, the author's impact was evaluated by the total citation number, the $\mathrm{h}$-index and the m-index. In fact, the $\mathrm{m}$-index is defined as the h-index divided by the number of years since the first author publication (Hirsch, 2007). Table 3 represents 20 authors arranged by their number of publication, their impact, their h-index and m-index.

Table 3. The most 20 relevant authors ordered by the sum of times cited

\begin{tabular}{llllllll}
\hline Rank & Author & Country & TP & TC & h-index & PY start & m-index \\
\hline $\mathbf{1}$ & Heath, R. & England & 2 & 105 & 2 & 2006 & 0.153 \\
$\mathbf{2}$ & Buck, R. & USA & 2 & 75 & 2 & 1995 & 0.142 \\
$\mathbf{3}$ & Chaudhuri, A. & USA & 2 & 75 & 2 & 1995 & 0.142 \\
$\mathbf{4}$ & Mattila, A. S. & USA & 2 & 74 & 2 & 1996 & 0.142 \\
$\mathbf{5}$ & Anderson, E. & USA & 1 & 44 & 1 & 2004 & 0.167 \\
$\mathbf{6}$ & Phau, I. & Australia & 2 & 36 & 2 & 2013 & 0.333 \\
$\mathbf{7}$ & Lwin, M. & Australia & 2 & 36 & 2 & 2013 & 0.285 \\
$\mathbf{8}$ & Kim, Y. & South Korea & 2 & 31 & 2 & 2016 & 0.500 \\
$\mathbf{9}$ & Hornik, J. & Israel & 2 & 20 & 2 & 2016 & 0.500 \\
$\mathbf{1 0}$ & Ofir, C. & Israel & 2 & 20 & 2 & 2016 & 0.500 \\
$\mathbf{1 1}$ & Rachamim, M. & Israel & 2 & 20 & 2 & 2016 & 0.500 \\
$\mathbf{1 2}$ & Akbari, M. & Iran & 1 & 18 & 1 & 2015 & 0.250 \\
$\mathbf{1 3}$ & Barquero-Perez, O. & Spain & 2 & 12 & 1 & 2017 & 0.500 \\
$\mathbf{1 4}$ & Goya-Esteban, R. & Spain & 2 & 12 & 1 & 2017 & 0.500 \\
$\mathbf{1 5}$ & Lee, S. & South Korea & 2 & 10 & 2 & 2018 & 1 \\
$\mathbf{1 6}$ & Alvarado-Karste, D. & USA & 1 & 5 & 1 & 2020 & 1 \\
$\mathbf{1 7}$ & Ahmed, P. K. & Malaysia & 1 & 5 & 1 & 2018 & 0.500 \\
$\mathbf{1 8}$ & Bhatia, T. K. & USA & 2 & 4 & 2 & 2019 & 1 \\
$\mathbf{1 9}$ & Kemp, E. & USA & 2 & 4 & 2 & 2015 & 0.400 \\
$\mathbf{2 0}$ & Anaza, N. A. & USA & 1 & 1 & 1 & 2020 & 1 \\
\hline
\end{tabular}

Source: Authors' own elaboration.

It can be noted that the most cited authors didn't exceed 2 published paper in the field of rational and emotional advertising in the last 28 years. The h-index doesn't exceed 2 and the m-index is less than 1 for most authors, which conveys the weak number of published studies on rational and emotional advertising. Furthermore, Heath, Buck, Chaudhuria and Mattila are the most cited authors. In fact, Heath is the most influential author with more than 100 citations. Moreover, The USA is the country where the topic is frequently studied. We found that 7 authors among 20 are originally from USA and affiliated to American universities. Table 4 displays the top 10 universities making and publishing research about rational and emotional advertising ranked according to the sum of times cited. Also, we were able to observe that the publications in the studied topic are not continues in time from 1990 to 2020 for the majority of the authors. 
Table 4 . The most 10 relevant universities ordered by the sum of published paper citation

\begin{tabular}{lllllll}
\hline Rank & University & Country & TP & TC & h-index & PY start \\
\hline $\mathbf{1}$ & University of Texas system & USA & 6 & 228 & 4 & 2004 \\
$\mathbf{2}$ & University of Bath & England & 3 & 118 & 3 & 2006 \\
$\mathbf{3}$ & Pennsylvania Commonwealth System of & USA & 3 & 75 & 2 & 1996 \\
& Higher Education & & & & & \\
$\mathbf{4}$ & Fairfield University & USA & 2 & 75 & 2 & 1995 \\
$\mathbf{5}$ & Curtin University & Australia & 2 & 36 & 2 & 2013 \\
$\mathbf{6}$ & University of Texas Austin & USA & 2 & 20 & 2 & 2016 \\
$\mathbf{7}$ & Bar Ilan University & Israel & 2 & 20 & 2 & 2016 \\
$\mathbf{8}$ & Pennsylvania State University & USA & 3 & 12 & 1 & 2017 \\
$\mathbf{9}$ & Universidad Rey Juan Carlos & Spain & 3 & 12 & 1 & 2017 \\
$\mathbf{1 0}$ & University of North Carolina & USA & 3 & 4 & 1 & 2007 \\
\hline
\end{tabular}

Source: Authors' own elaboration.

According to the table, we can see that the total published paper by universities on rational and emotional studies is weak and doesn't exceed in the best case 6 research papers by university for a period of time of 16 years. It appears clearly that the USA universities constitute the leader, among all universities over the world in the studied topic. In fact, 6 universities among 10 are from the USA, followed by those in England, Australia, Israel and Spain. The American universities started their studies in rational and emotional advertising, 25 years ago and reached a total of 524 papers citations.

In summary, all previous results, allow us to answer the first research question: How has the advertising literature addressing rational and emotional concepts evolve so far?

Indeed, the findings show that the research in rational and emotional advertising started in 1992 and reached its peak in 2019 with 26 published paper. The WoS database contains 256 records in different documents format related to rational and emotional advertising. However, there is only 96 published articles in the studied topic. We noted that American authors and universities are ranked in the first position with 32 published paper cited 524 times. Despite this, the quantity of published research in rational and emotional advertising is weak with only 96 published documents in 30 years. This means that the research productivity for the efficiency of rational and emotional advertising is approximatively 4 published articles by year. Which is still not enough to develop this topic, compared to the number of published papers on emotional advertising and rational advertising separately, which reached respectively 836 and 263, according to the WoS (2021).

\section{d. Journals}

Published papers on rational and emotional advertising have been in the majority published in business and management field's journals. Table 5 represent the journals rating according to the total of published papers in this topic (PP), the percentage ratio of the topic compared to all publications ( $\mathrm{PP} / \mathrm{TP})$, the total published paper related to the topic citations, the h-index and the m-index. 
Table 5. The most relevant journals ordered by the sum of published paper in the studied topic

\begin{tabular}{|c|c|c|c|c|c|c|c|c|c|}
\hline Rank & Journal & Country & $\mathbf{T P}^{1}$ & PP & $\% \mathrm{PP} / \mathrm{TP}$ & TC & h-index & PY start & m-index \\
\hline 1 & $\begin{array}{l}\text { Journal of Advertising } \\
\text { Research }\end{array}$ & USA & 778 & 9 & 1.156 & 287 & 7 & 1997 & 0.500 \\
\hline 2 & Journal of Business Research & USA & 5156 & 6 & 0.116 & 159 & 5 & 1973 & 0.178 \\
\hline 3 & $\begin{array}{l}\text { International Journal of } \\
\text { Market Research }\end{array}$ & USA & 641 & 3 & 0.468 & 64 & 3 & 1984 & 0.500 \\
\hline 4 & $\begin{array}{l}\text { International Journal of } \\
\text { Advertising }\end{array}$ & England & 454 & 3 & 0.660 & 59 & 3 & 1996 & 0.272 \\
\hline 5 & $\begin{array}{l}\text { Communication and } \\
\text { Society-Spain }\end{array}$ & Spain & 576 & 3 & 0.520 & 2 & 1 & 2005 & 0.500 \\
\hline 7 & Journal of Advertising & England & 629 & 2 & 0.317 & 134 & 2 & 1997 & 0.080 \\
\hline 9 & $\begin{array}{l}\text { Journal of Health } \\
\text { Communication }\end{array}$ & USA & 1565 & 2 & 0.127 & 56 & 2 & 1999 & 0.083 \\
\hline 6 & $\begin{array}{l}\text { European Journal of } \\
\text { Marketing }\end{array}$ & England & 1032 & 2 & 0.193 & 31 & 1 & 2008 & 0.166 \\
\hline 8 & Journal of Social Marketing & England & 154 & 2 & 1.298 & 25 & 1 & 2011 & 0.167 \\
\hline 10 & $\begin{array}{l}\text { Journal of Social Behavior and } \\
\text { Personality }\end{array}$ & USA & 2626 & 2 & 0.076 & 10 & 2 & 1997 & 0.200 \\
\hline 11 & Journal of Sustainability & Switzerland & 16474 & 2 & 0.012 & 7 & 2 & 2009 & 1 \\
\hline 12 & Journal of world Englishes & USA & 318 & 2 & 0.006 & 4 & 2 & 2010 & 1 \\
\hline 13 & $\begin{array}{l}\text { African journal of business } \\
\text { management }\end{array}$ & Nigeria & 4120 & 1 & 0.002 & 11 & 1 & 2007 & 0.250 \\
\hline
\end{tabular}

Note. ${ }^{1}$ Total number of publications for each journal at the time of the analysis that are retrievable in the in Cites.

Source: Authors' own elaboration.

The results show that in terms of productivity, the journal of advertising research is the best ranked journal. In fact, in a total of 778 published paper since the journal's creation, 9 published paper (PP) were devoted to the efficiency of rational and emotional advertising and cited 287 times. However, the ratio percentage doesn't exceed $1.15 \%$, which still very weak knowing that the first journal issue appeared in 1997. Moreover, journals specialized in advertising appear to be more representative of all journals publications in rational and emotional advertising efficiency. It was addressed by $2 \%$ of all publications and got 480 citations. However, we note that the first ranked journal h-index is double compared to the third journal on the list, the international journal of market research. This means that the first journal articles in the field were cited at least 2 times more than those from the third ranked journal.

According to our analysis, the answer to the second research question about the most cited journals worth consulting for future research in this field, appear clearly. In fact, the journals specialized in advertising are the first among all other journals with 14 published paper and 480 citations for the studied topic. Followed by journals specialized in business fields with 7 publications and 170 citations, marketing research with 7 published papers and 120 citations and journals devoted to communication with the same number of published articles and 62 citations. Finally, journals devoted to consumer behavior with 2 published research and 10 citations.

\section{e. $\quad$ Science mapping analysis}

The objective of this study is to obtain a global perspective of research evolution on rational and emotional advertising, by identifying the conceptual, intellectual, and social diemnsions of the topic under investigation. In this section, we will try to answer the last research question about the research concepts related to rational and emotional advertising, and which one deserves further consideration in prospective advertising studies?

This mapping analysis will focus on the terms connected to rational and emotional study based on co-occurreces (Boyack \& Klavans, 2010). Those co-occurrences were recognized by using the links between the keywords plus that have been generated by the WoS for each published paper in the dataset. In fact, the 30 most cited keywords were connected to each other following the association strength. The results are presented in Figure 3. 


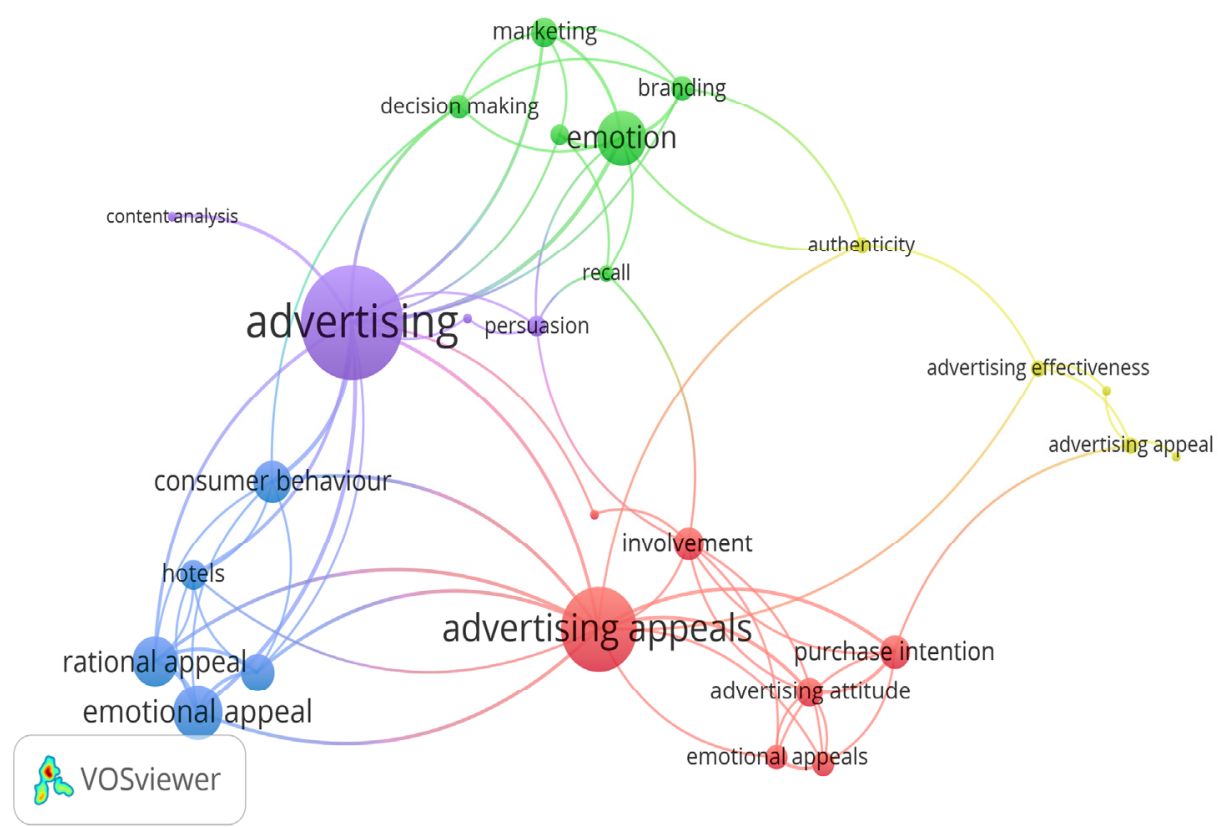

Figure 3. The conceptual structure based on keywords association strength

Source: VOSviewer based on WoS dataset.

According to this schema, co-occurrences were identified. In fact, the network map shows that the word "advertising" is connected to three words' clusters presented with different colors. Indeed, if the keywords were used at the same time by authors, they appeared close to each other and well linked. The size of the word bubble depends on the times it was used by the authors. Different colors define each cluster. In this case, five clusters can be distinguished: i) Advertising (purple); ii) Advertising appeals (red); iii) Emotion (green); iv) Rational appeal (blue); v) Advertising effectiveness (yellow).

As we can see through the map, rational and emotional advertising were most studied in two contexts: hotels and Website promotions. Also, rational advertising is linked to consumer behavior. However, emotional advertising is linked to consumer behavior, purchase intention, decision making and branding.

Through the co-occurrence technique, we were able to identify the social concepts and intellectual structure (Peters \& van Raan, 1991). In fact, by analyzing groups of co-authors, we have been able to identify the countries collaborations for scientific publications as shown in the Figure 4.

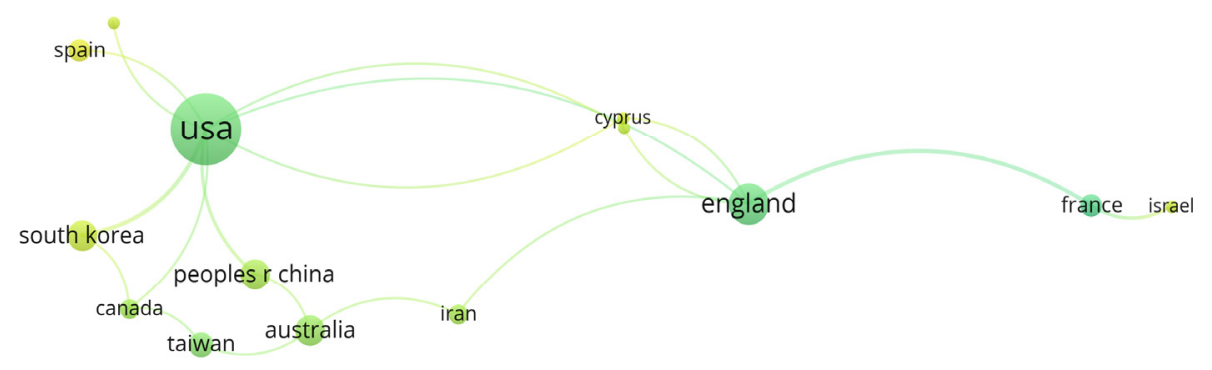

\& vosviewer

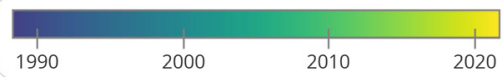

Figure 4. The social structure based on co-authors association strength 
Rational and emotional advertising' documents co-authorship structure, as represented in the map, shows that in the past 30 years, a strong collaboration between authors coming from developed countries like the USA, England, France, Canada and Australia and different other countries around the world. Indeed, authors in the USA collaborate with others coming from Asia (Singapore; South Korea and China), from Canada and Europe especially Spain, Cyprus and Ukraine. On the other hand, British researchers collaborate with European authors especially those from France, Cyprus and Ukraine plus others coming from Asia, namely Iran.

Furthermore, Australian authors publish scientific papers in collaboration with authors coming from Taiwan, UAE and Iran. This shows that their entire collaborations are limited to Asian countries. Finally, French authors works with those from Israel and Canadian with those from USA, Taiwan and South Korea.

According to these results, we can confirm that the research on rational and emotional advertising was and still dominated by developed countries. Also, the scientific collaboration, especially for co-authorship between developed countries is the most common. However, the co-authorship between undeveloped and developed countries is still very weak during the past 30 years.

In order to complete the science mapping analysis, we studied the co-citation for the past 30 years for all data base documents. Figure 5 represents the co-citation evolution over the time.

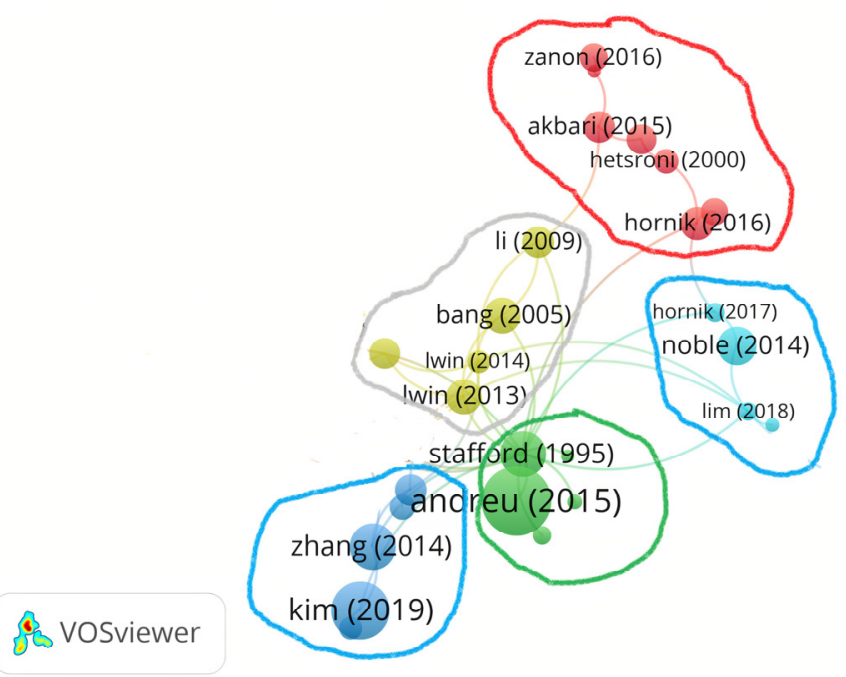

Figure 5. The historic evolution of co-citations among the 30 most relevant research paper

Source: VOSviewer based on WoS dataset.

The co-citations evolution from 1990 to 2020 for the 30 most relevant research shows 5 author groups by using a boarder perspective (Rothaermel et al., 2007). In fact, each group represents a team of authors who studied the rational and emotional advertising field by citing each other's. Indeed, this co-citation evolution can be summarized as follow:

The period 2013-2019 (Blue) works: Zang (2014) and Kim (2019) studied the relationship between rational and emotional advertising messages and consumer response in the service sector. Their studies tried to explain the role of rational and emotional advertising promotion in the existence of spatial distance, or on the influence of consumer culture orientation and in the case of different products types. This group of authors focused its study on understanding rational and emotional message' persuasion power.

The period 2008-2018 (light Blue) works: this group of authors performed a rational and emotional messages analysis based on gender. In fact, the main author Lim (2018) studied the effects of sequencing rational and emotional messages on corporate and product brand attitudes. Indeed, authors in this group focused on the rational and emotional messages differences in consumer understanding due to consumer's gender. Their studies investigate the case of social advertising and product brand attitudes.

The period 2000-2018 (Red Slice) works: in this period of time, authors studied the impact of attitude and values on emotional advertising and purchasing intention. The most influential author is Hornik (2016), who did a meta-analysis about quantitative evaluation of emotional advertising. Hence, authors in this group investigate the 
emotional advertising effectiveness in campaign success (Binet, 2009), products (Akbari, 2015), eco-friendly accommodations (Zanon, 2016) and financial services (Mogaji, 2018).

The period 2005-2014 (Yellow) works: Authors from this period focused on the international appliance differences for the advertisement messages. In fact, Bang (2005) studied the advertising messages quality for the USA and Korean companies. Followed by Li (2009) who explores the advertising messages strategies in China's multinational companies. However, the research of Iwin (2014) can be considered as the most important paper in this group. He focused in his study on the moderating role of rational and emotional advertising message in the case of hotels boutiques. This research is linked to 7 others authors groups in the map.

The period 1995-2014 (Green) works: Articles in this period were devoted to the rational and emotional message effectiveness. In fact, Stafford (1995) is the most co-cited author in this group and the most dominant one, his work is linked to 16 others papers from different periods of time. The rational and emotional advertising effectiveness was studied by those authors for internet advertising messages (Yang, 2004) and online advertisement (Behboudi, 2014). Furthermore, this effectiveness was also investigated in retail services (Stafford, 1995) and in consumer brand relationship (Pang, 2009).

Finally, according to our analysis, we can conclude, as an answer to the third research question that studies about rational and emotional advertising messages had focused on brands, products, services and online advertising. These studies were conducted, wether with collaboration or not, by developed countries. On the other hand, the co-citation evolution is characterized by the existence of different authors groups. Each group focused its analysis on diverse sectors trying to investigate rational and emotional advertising messages' effectiveness. According to the authors, this effectiveness depends on the consumers' attitude, gender, values, culture and purchasing intention.

\section{Conclusion, Limitations and Future Research Avenues}

This study analyzes the evolution of scientific research on rational and emotional advertising between 1990 and 2020 in terms of available publications in the Web of Science database. The results provide an overview of some or all existing information about research on rational and emotional advertising. This study provides a review of the literature and summarizes the research available to date.

In conclusion, this study offered an overview of the literature addressing rational and emotional advertising messages. A number of bibliometric analysis techniques were performed to estimate the scientific production's quality by performing a science mapping analysis in order to explore the topic's social and intellectual structures. In order to get the productivity ratio, we used different bibliometric indicators like total publication, total citations and h-index, for journals, authors and countries.

Answering the first research question $(R Q 1)$, we proved that in the past 30 years, the scientific production of the studied topic is weak because it doesn't exceed an average of four published papers by year. Furthermore, all this production is dominated by developed countries especially the USA. In this logic, collaboration between undeveloped countries and developed ones should be encouraged. Also, the results show that scientific production of rational and emotional advertising studies is in majority published in advertising journals, followed by business journals fields, Marketing research and communication journals and finally consumer behavior journals. This answers the second research question $(R Q 2)$.

We had completed our bibliometric analysis by elaborating a science mapping. In fact, we used a co-occurrence of keywords and co-authorship and a co-citation history for the 30 most significant published papers in order to reveal the topic's conceptual, intellectual and social research organization. Our keywords' co-occurrences analysis distinguished many thematic clusters which are: i) Advertising; ii) Advertising appeals; iii) Emotion; iv) Rational appeal; and v) Advertising effectiveness. Finally, we end our analysis by answering the third research question (RQ3). The analysis shows that studies about rational and emotional advertising effectiveness had focused on brands, products, services and online advertising. The effectiveness of these advertising messages is affected by the consumers' attitude, gender, values, culture and purchasing intention.

However, this study is not free from limitations. In fact, the bibliometric study's main problem is the prevalent bias in the indicators used to measure the quantity, quality and relations between publications. Often, the citation index or the number of publications that measure the quality or quantity, regardless of the paper's actual quality. The fact that an author is important or relevant convinces other authors to cite him without reading the article or developing a critical view of its content. Another limitation of the study is that many other articles on rational and emotional advertising exist in non-indexed journals which are not available in the WoS database.

For future research, researchers should consider conducting a bibliometric analysis using other databases. 
Google Scholar, for example, includes not only quotes in the journals available on ISI Web of Science, but also quotes in other academic documents available on the Internet. Other research could also compare the results of other databases with those of this research. However, other scientific productions on rational and emotional advertising are present in non-indexed journals in the Thomson Reuters Web of Science with impact factors in the Journal Citation Report (JCR).

Finally, this study can be useful for both scholars and practitioners who are studying or exploring this topic and want to have a complete overview of the scientific literature produced thus far.

\section{References}

Ajzen, I. (2001). Nature and operation of attitudes. Annual Review of Psychology, 52(1), 27-58. https://doi.org/10.1146/annurev.psych.52.1.27

Alden, D. L., Steenkamp, J. B. E., \& Batra, R. (1999). Brand positioning through advertising in Asia, North America, and Europe: The role of global consumer culture. Journal of Marketing, 63(1), 75-87. https://doi.org/10.1177/002224299906300106

Börner, K., Chen, C., \& Boyack, K. W. (2003). Visualizing knowledge domains. Annual Review of Information Science and Technology, 37(1), 179-255. https://doi.org/10.1002/aris.1440370106

Bouyssou, D., \& Marchant, T. (2011). Bibliometric rankings of journals based on impact factors: An axiomatic approach. Journal of Informetrics, 5(1), 75-86. https://doi.org/10.1016/j.joi.2010.09.001

Boyack, K. W., \& Klavans, R. (2010). Co-citation analysis, bibliographic coupling, and direct citation: Which citation approach represents the research front most accurately? Journal of the American Society for information Science and Technology, 61(12), 2389-2404. https://doi.org/10.1002/asi.21419

Broadus, R. N. (1987). Toward a definition of "bibliometrics". Scientometrics, 12(5-6), 373-379. https://doi.org/10.1007/BF02016680

Butt, I., Bhasker, M., \& Mahmud, A. S. (2017). Relevance of soft-sell and hard-sell advertising appeals for global consumer cultural positioning. Journal of Customer Behaviour, 16(3), 263-279. https://doi.org/10.1362/147539217X15071081721125

Buzzell, R. D. (1968). Can you standardize multinational marketing (pp. 102-113)? Reprint Service, Harvard business review.

Cadavid Higuita, L., Awad, G., \& Franco Cardona, C. J. (2012). A bibliometric analysis of a modeled field for disseminating innovation. Estudios Gerenciales, 28(SPE), 213-236. https://doi.org/10.18046/j.estger.2012.1486

Campbell, K., Naidoo, J., \& Campbell, S. (2020). Hard or Soft Sell? Understanding White Papers as Content Marketing. IEEE Transactions on Professional Communication, 21-38. https://doi.org/10.1109/TPC.2019.2961000

Cobo, M. J., López-Herrera, A. G., Herrera-Viedma, E., \& Herrera, F. (2012). SciMAT: A new science mapping analysis software tool. Journal of the American Society for Information Science and Technology, 63(8), 1609-1630. https://doi.org/10.1002/asi.22688

Coulter, R. A., Zaltman, G., \& Coulter, K. S. (2001). Interpreting consumer perceptions of advertising: An application of the Zaltman Metaphor Elicitation Technique. Journal of Advertising, 30(4), 1-21. https://doi.org/10.1080/00913367.2001.10673648

Cuccurullo, C., Aria, M., \& Sarto, F. (2016). Foundations and trends in performance management. A twenty-five years bibliometric analysis in business and public administration domains. Scientometrics, 108(2), 595-611. https://doi.org/10.1007/s11192-016-1948-8

Dada, O. (2018). A model of entrepreneurial autonomy in franchised outlets: A systematic review of the empirical evidence. International Journal of Management Reviews, 20(2), 206-226. https://doi.org/10.1111/ijmr.12123

Daim, T. U., Rueda, G., Martin, H., \& Gerdsri, P. (2006). Forecasting emerging technologies: Use of bibliometrics and patent analysis. Technological Forecasting and Social Change, 73(8), 981-1012. https://doi.org/10.1016/j.techfore.2006.04.004

De Canio, F., Martinelli, E., \& Endrighi, E. (2021). Enhancing consumers' pro-environmental purchase intentions: The moderating role of environmental concern. International Journal of Retail \& Distribution 
Management, 49(9), 1312-1329 https://doi.org/10.1108/JJRDM-08-2020-0301

Eck, N. J. V., \& Waltman, L. (2009). How to normalize cooccurrence data? An analysis of some well-known similarity measures. Journal of the American Society for Information Science and Technology, 60(8), 1635-1651. https://doi.org/10.1002/asi.21075

El Bardai H. (2020). Soft-sell versus hard-sell: Quelle approche publicitaire dans les pays arabo-musulmans? Une étude exploratoire au Maroc et en Arabie Saoudite. Projectics / Proyéctica / Projectique, 3(27), 75-96. https://doi.org/10.3917/proj.027.0075

Elinder, E. (1965). How international can European advertising be? Journal of Marketing, 29(2), 7-11. https://doi.org/10.1177/002224296502900203

Fatt, A. C. (1967). The danger of "local" international advertising. Journal of Marketing, 31(1), 60-62. https://doi.org/10.1177/002224296703100114

Garfield, E. (2004). Historiographic mapping of knowledge domains literature. Journal of Information Science, 30(2), 119-145. https://doi.org/10.1177/0165551504042802

Grunert, K. G., Scholderer, J., \& Rogeaux, M. (2011). Determinants of consumer understanding of health claims. Appetite, 56(2), 269-277. https://doi.org/10.1016/j.appet.2011.01.009

Haisley, E., \& Loewenstein, G. (2011). It's not what you get but when you get it: The effect of gift sequence on deposit balances and customer sentiment in a commercial bank. Journal of Marketing Research, 48(1), 103-115. https://doi.org/10.1509/jmkr.48.1.103

Haque, A., Ahmed, K., \& Jahan, S. I. (2010). Shariah observation: Advertising practices of Bank Muamalat in Malaysia. Journal of Islamic Marketing, 1(1), 70-77. https://doi.org/10.1108/17590831011026240

Hennig-Thurau, T., Henning, V., \& Sattler, H. (2007). Consumer file sharing of motion pictures. Journal of Marketing, 71(4), 1-18. https://doi.org/10.1509/jmkg.71.4.001

Hirsch, J. E. (2005). An index to quantify an individual's scientific research output. Proceedings of the National academy of Sciences, 102(46), 16569-16572. https://doi.org/10.1073/pnas.0507655102

Hirsch, J. E. (2007). Does the h index have predictive power? Proceedings of the National Academy of Sciences, 104(49), 19193-19198. https://doi.org/10.1073/pnas.0707962104

Hornik, J., Ofir, C., \& Rachamim, M. (2016). Quantitative evaluation of persuasive appeals using comparative $\begin{array}{llll}\text { meta-analysis. The } & \text { Review, 192-222. }\end{array}$ https://doi.org/10.1080/10714421.2016.1195204

Ivanov, B., Dillingham, L. L., Parker, K. A., Rains, S. A., Burchett, M., \& Geegan, S. (2018). Sustainable attitudes: Protecting tourism with inoculation messages. Annals of Tourism Research, 73, 26-34. https://doi.org/10.1016/j.annals.2018.08.006

Loda, M. D., \& Coleman, B. C. (2005). Sequence matters: A more effective way to use advertising and publicity. Journal of Advertising Research, 45(4), 362-372. https://doi.org/10.1017/S0021849905050464

Luqmani, M., Zahir, Q., \& Ugur, Y. (1989). Advertising in Saudi Arabia: Content and Regulation. International Marketing Review, 31(3), 35-39. https://doi.org/10.1002/tie.5060310311

Lutz, R. J., MacKenzie, S. B., \& Belch, G. E. (1983). Attitude toward the ad as a mediator of advertising effectiveness: Determinants and consequences. ACR North American Advances.

McCullough, M. E., Tsang, J. A., \& Emmons, R. A. (2004). Gratitude in intermediate affective terrain: Links of grateful moods to individual differences and daily emotional experience. Journal of Personality and Social Psychology, 86(2), 295. https://doi.org/10.1037/0022-3514.86.2.295

McGarry, E. D. (1958). The propaganda function in marketing. Journal of Marketing, 23(2), 131-139. https://doi.org/10.1177/002224295802300202

Mehta, A. (2000). Advertising attitudes and advertising effectiveness. Journal of Advertising Research, 40(3), 67-72. https://doi.org/10.2501/JAR-40-3-67-72

Merig'o, J. M., Cancino, C. A., Coronado, F., \& Urbano, D. (2016). Academic research in innovation: A country analysis. Scientometrics, 108, 559-593. https://doi.org/10.1007/s11192-016-1984-4

Merigó, J. M., Mas-Tur, A., Roig-Tierno, N., \& Ribeiro-Soriano, D. (2015). A bibliometric overview of the Journal of Business Research between 1973 and 2014. Journal of Business Research, 68(12), 2645-2653. 
https://doi.org/10.1016/j.jbusres.2015.04.006

Mitchell, A. A., \& Olson, J. C. (1981). Are product attribute beliefs the only mediator of advertising effects on brand attitude? Journal of Marketing Research, 18(3), 318-332. https://doi.org/10.1177/002224378101800306

Mueller, B. (1987). Reflections Of Culture: An Analysis Of Japanese And American Advertising Appeals. Journal of Advertising Research, 51-59.

Noyons, E., Moed, H., \& Van Raan, A. (1999). Integrating research performance analysis and science mapping. Scientometrics, 46(3), 591-604. https://doi.org/10.1007/BF02459614

Okazaki, S., Mueller, B., \& Taylor, C. R. (2010). Global Consumer Culture Positioning: Testing Perceptions Of Soft-Sell And Hard-Sell Advertising Appeals Between U.S And Japanese Consumers. Journal Of International Marketing, 20-34. https://doi.org/10.1509/jimk.18.2.20

Peters, H., \& Van Raan, A. (1991). Structuring scientific activities by co-author analysis: An expercise on a university faculty level. Scientometrics, 20(1), 235-255. https://doi.org/10.1007/BF02018157

Pollay, R. W., \& Mittal, B. (1993). Here's the beef: Factors, determinants, and segments in consumer criticism of advertising. Journal of Marketing, 57(3), 99-114. https://doi.org/10.1177/002224299305700307

Purnawirawan, N., De Pelsmacker, P., \& Dens, N. (2012). Balance and sequence in online reviews: How perceived usefulness affects attitudes and intentions. Journal of Interactive Marketing, 26(4), 244-255. https://doi.org/10.1016/j.intmar.2012.04.002

Quelch, J. A., \& Hoff, E. (1986). Customizing Global Marketing. Harvard Business, 59-68. https://doi.org/10.1002/tie.5060280204

Rey-Martí, A., Ribeiro-Soriano, D., \& Palacios-Marqu'es, D. (2016). A bibliometric analysis of social entrepreneurship. J. Bus. Res., 69(5), 1651-1655. https://doi.org/10.1016/j.jbusres.2015.10.033

Rothaermel, F. T., Agung, S. D., \& Jiang, L. (2007). University entrepreneurship: A taxonomy of the literature. Industrial and Corporate Change, 16(4), 691-791. https://doi.org/10.1093/icc/dtm023

Safraou-Ouadrani, I., \& Guiot, D. (2010). Les Publicités Emotionnelles: Quelle Efficacité Auprès Des Personnes Agées. Acte Du 26ème Congrès International De L'afm.

Statista research department. (2019). Dépenses publicitaires par média en Amérique du nord 2015-2021. Retreived

from https://fr.statista.com/statistiques/1028919/depenses-publicitaires-par-media-amerique-du-nord/

Stern, H. (1962). The significance of impulse buying today. Journal of Marketing, 26(2), 59-62. https://doi.org/10.1177/002224296202600212

Vanclay, J. K. (2007). On the robustness of the h-index. Journal of the American Society for Information Science and Technology, 58(10), 1547-1550. https://doi.org/10.1002/asi.20616

Waltman, L., Van Eck, N. J., \& Noyons, E. C. (2010). A unified approach to mapping and clustering of bibliometric networks. Journal of Informetrics, 4(4), 629-635. https://doi.org/10.1016/j.joi.2010.07.002

Wei Chen, C., Chi Shen, C., \& Yuchine, W. (2007). Marketing Communication Stratégies In Support Of Product Launch: An Empirical Study Of Taiwanese High-Tech Firms. Industrial Marketing Management, 1046-1056. https://doi.org/10.1016/j.indmarman.2006.08.002

\section{Copyrights}

Copyright for this article is retained by the author, with first publication rights granted to the journal.

This is an open-access article distributed under the terms and conditions of the Creative Commons Attribution license (http://creativecommons.org/licenses/by/4.0/). 